\title{
Antibody responses after two doses of CoronaVac of the participants with or without the diagnosis of COVID-19
}

\author{
Derya Ozturk $^{1} \cdot$ Nesrin Gareayaghi $^{2} \cdot$ Ceren Atasoy Tahtasakal $^{3} \cdot$ Mustafa Calik $^{4}\left(\mathbb{C}^{\circ} \cdot\right.$ Ertugrul Altinbilek $^{1}$
}

Received: 20 October 2021 / Accepted: 1 December 2021 / Published online: 10 January 2022

(c) The Author(s), under exclusive licence to Royal Academy of Medicine in Ireland 2021

\begin{abstract}
Background CoronaVac, an inactivated whole-virion vaccine against COVID-19, has been shown to be safe with acceptable antibody responses by various clinical trials.

Aims The objective was to investigate the post-vaccination antibody levels of both symptomatic and asymptomatic healthcare workers with or without the diagnosis of COVID-19 in an emergency department (ED) of a hospital serving as a pandemic hospital.

Methods This single-centred, prospective study was conducted on 86 participants who were working as nurse or doctor in the ED. The volunteers were older than 18 years and either positive or negative for either computed tomography (CT), realtime reverse transcription polymerase chain reaction (qRT-PCR), or both. Thirty days after the second dose of CoronaVac $(3 \mu \mathrm{g})$, the antibody levels were chemiluminescent microparticle immunoassay.

Results Mean age of all participants were 33.1 \pm 9.1 years. The antibody levels in the qRT-PCR $(+)$ and CT( + ) groups were significantly higher than the qRT-PCR $(-)$ and $\mathrm{CT}(-)$ groups, respectively $(p<0.05)$. In the $\mathrm{CT}(+) / \mathrm{qRT}-\mathrm{PCR}(+)$ group, the antibody level was significantly higher than the CT( - )/qRT-PCR $(-)$ and CT( $(-) / \mathrm{qRT}-\mathrm{PCR}(+)$ or CT(+)/qRT-PCR (-) group $(p<0.05)$. On the other hand, antibody levels in the hospitalized group were significantly higher than in the non-hospitalized group $(p<0.05)$. A significant positive correlation was observed between the time elapsed after vaccination and antibody levels of the participants $(r=0.343 ; p=0.000)$.

Conclusion In conclusion, antibody responses of recovered patients COVID-19 diagnosed by both CT and qRT-PCR were much robust than the patients diagnosed by either one of the techniques or undiagnosed/disease-free participants suggesting that severity of the disease likely contributes to the antibody responses after vaccination with CoronaVac.
\end{abstract}

Keywords Computed tomography $\cdot$ CoronaVac $\cdot$ COVID-19 $\cdot$ qRT-PCR

\section{Introduction}

Mustafa Calik

drmustafacalik@yahoo.com

1 Department of Emergency Medicine, University of Health Sciences, Sisli Hamidiye Etfal Training and Research Hospital, Halaskargazi St, 34371 Sisli/Istanbul, Turkey

2 Department of Microbiology, University of Health Sciences, Sisli Hamidiye Etfal Training and Research Hospital, Halaskargazi St, 34371 Sisli/Istanbul, Turkey

3 Department of Infectious Diseases, University of Health Sciences, Sisli Hamidiye Etfal Training and Research Hospital, Halaskargazi St, 34371 Sisli/Istanbul, Turkey

4 Department of Emergency Medicine, University of Health Sciences, Gaziosmanpaşa Training and Research Hospital, Osmanbey St, 34255 Gaziosmanpasa/Istanbul, Turkey
The coronavirus-19 disease (COVID-19) pandemic continues to affect the societies differentially due to the inequality in the healthcare systems and socioeconomical status [1-3]. The literature indicates that the patients who recover from COVID-19 develop cellular immune response and antibodies against the virus for an estimated duration longer than 6 months directing to the development of COVID-19 vaccines [4-6]. There are various methods performed in the development of vaccines including inactivated virus and nucleic acid-based vaccines (DNA and RNA vaccines) [7]. Furthermore, more than 85 vaccines under development are used in clinical trials [8].

Inactivated vaccines have been widely researched and commonly used to provide protection against various 
infectious diseases including respiratory infections [9]. Possible advantages of the inactivated vaccines include their non-replicable in the host and non-transmittable nature [10], inducing both cellular and humoral immunity [11] and easy storage and shipment [12]. The disadvantages of inactivated vaccines, on the other hand, include less immunogenicity, huge amount of virus to be dealt with, and requirement of verification of the antigens/epitopes [13] Although the development and inactivation methods of the inactivated virus vaccines are akin, the isolated virions and adjuvants used in the process differ [7, 9, 14].

In a previous double-blind, randomised, placebo-controlled study conducted in Turkey, efficacy and safety of an inactivated whole-virion SARS-CoV-2 vaccine (CoronaVac) were investigated on subjects aged between 18- and 59-year-old adults who were both seronegative and real-time reverse transcription polymerase chain reaction (qRT-PCR)-negative for the COVID-19 and were administered with two doses of CoronaVac [10]. In this study, we aimed to compare the postvaccination antibody levels of symptomatic and asymptomatic healthcare workers with or without the diagnosis of COVID19 in the emergency department (ED) of a tertiary education and research hospital serving as a pandemic hospital.

\section{Material and methods}

\section{Study design and participants}

Our study was designed as a single-centred, prospective study. The study was approved by the clinical research ethics committee of our hospital (Date: 02/03/2021, Number: 1811). A total of 86 healthcare workers (doctors and nurses) working in the ED of a pandemic hospital who volunteered to participate in the study and had a positive or negative COVID-19 qRT-PCR test before March 2021 and received two doses of CoronaVac $(3 \mu \mathrm{g})$ during the vaccination period were included. The exclusion criteria of the study were to be under the age of 18 , to be healthcare worker working in different clinics, not to be health personnel (nurse or doctor), and to be unvaccinated personnel. Moreover, healthcare workers who received other medications such as antibiotics, corticosteroids, or antipyretics after second dose of vaccination were not included in the study.

After 30 days of second dose of vaccination, volunteers were invited to the hospital. Medical records (blood type, comorbidity, length of hospital stay, computed tomography (CT) of the chest results, qRT-PCR results) and demographical characteristics (age and gender) of the participants were investigated. Moreover, serum samples were collected from the volunteers in order to determine the antibody responses of the participants.

\section{Serological chemiluminescence immunoassay for SARS-CoV-2}

Quantitative detection of immunoglobulin class G ( $\operatorname{IgG}$ ) antibodies, including neutralizing antibodies against the receptor-binding region (RBD) of the spike protein $\mathrm{S} 1$ subunit of SARS-CoV-2 were determined by performing the chemiluminescent microparticle immunoassay (CMIA) method in the serum samples obtained in this study. The serum samples were analysed using the SARS-CoV-2 IgG test (ARCHITECT IgG II Quant test, Abbott, USA) on an ARCHITECT immunoassay analyser.

The results obtained from all serum samples analysed were evaluated as arbitrary unit $/ \mathrm{mL}(\mathrm{AU} / \mathrm{mL})$. The cutoff value was set at $50.0 \mathrm{AU} / \mathrm{mL}$, and values lower than 50.0 $\mathrm{AU} / \mathrm{mL}$ were evaluated as negative while values equal to or higher than $50.0 \mathrm{AU} / \mathrm{mL}$ were evaluated as positive. In addition, the concentrations obtained in $\mathrm{AU} / \mathrm{mL}$ can be multiplied by the correlation coefficient of 0.142 and converted to the "binding antibody unit (BAU/mL)" in the WHO's International Standard for anti-SARS-CoV-2 immunoglobulin [15]. Accordingly, concentrations of $50 \mathrm{AU} / \mathrm{mL}$ or 7.1 $\mathrm{BAU} / \mathrm{mL}$ and above can be considered positive. It was also reported that this test was $100 \%$ compatible with the plaque reduction neutralization test (PRNT), and a concentration of $1050 \mathrm{AU} / \mathrm{mL}$ was associated with a 1:80 dilution of PRNT [16].

\section{Statistical analysis}

All statistical analyses were conducted by using Statistical Package for the Social Sciences version 27.0 (SPSS 27.0; IBM). In the descriptive statistics of the data, mean, standard deviation (SD), median, lowest, highest, frequency, and ratio values were used. The distribution of variables was analysed by Kolmogorov-Smirnov test. Kruskal-Wallis and Mann-Whitney $U$ tests were used in the analysis of quantitative independent data. Wilcoxon signed rank test was used in the analysis of quantitative dependent data. Spearman correlation test was used in the correlation analysis.

\section{Results}

The mean age of all participants were $33.1 \pm 9.1$ years $(\min -\max =21.0-58.0$ and median $=29.0)$ and most of the participants were 20-29 years old (Table 1). Of all participants, 45 of them (52.3\%) were female, and 41 of them $(47.7 \%)$ were male. Most of the participants $(n=73$; $84.9 \%$ ) did not have any comorbid diseases including hypertension, diabetes mellitus, chronic obstructive pulmonary 
Table 1 Participants' characteristics. (Note: Data are expressed as numbers $(n)$, percentages $(\%)$, or minimummaximum (min-max) and mean \pm standard deviation $(\mathrm{SD}))$

\begin{tabular}{|c|c|c|c|c|}
\hline & & Min-max & Median & Mean \pm SD $/ n(\%)$ \\
\hline \multirow[t]{3}{*}{ Age } & $20-29$ & & & $44(51.2)$ \\
\hline & $30-39$ & & & $20(23.3)$ \\
\hline & $\geq 40$ & & & $22(25.6)$ \\
\hline \multirow[t]{7}{*}{ Blood type } & $0(+)$ & & & $30(34.9)$ \\
\hline & $0(-)$ & & & $1(1.2)$ \\
\hline & $\mathrm{A}(+)$ & & & $41(47.7)$ \\
\hline & $\mathrm{A}(-)$ & & & $1(1.2)$ \\
\hline & $\mathrm{B}(+)$ & & & $8(9.3)$ \\
\hline & $\mathrm{B}(-)$ & & & $3(3.5)$ \\
\hline & $\mathrm{AB}(+)$ & & & $2(2.3)$ \\
\hline \multirow[t]{2}{*}{ Antibody levels (AU/mL) } & Pre-vaccination & $0.1-10.0$ & 3.1 & $4.1 \pm 4.0$ \\
\hline & Post-vaccination & $0.9-3004.7$ & 448.0 & $649.7 \pm 652.8$ \\
\hline Days to vaccination & & $0.0-398.0$ & 0.0 & $98.6 \pm 140.1$ \\
\hline \multirow[t]{2}{*}{ qRT-PCR result } & $(-)$ & & & $50(58.1)$ \\
\hline & $(+)$ & & & $36(41.9)$ \\
\hline \multirow[t]{2}{*}{$\mathrm{CT}$ result } & $(-)$ & & & $66(76.7)$ \\
\hline & $(+)$ & & & $20(23.3)$ \\
\hline CT(-)/qRT-PCR (-) & & & & $47(54.7)$ \\
\hline $\mathrm{CT}(+) / \mathrm{qRT}-\mathrm{PCR}(+)$ & & & & $17(19.8)$ \\
\hline $\begin{array}{c}\mathrm{CT}(-) / \mathrm{qRT}-\mathrm{PCR}(+) \text { or } \\
\mathrm{CT}(+) / \mathrm{qRT}-\mathrm{PCR}(-)\end{array}$ & & & & $22(25.6)$ \\
\hline \multirow[t]{2}{*}{ Hospitalization } & $(-)$ & & & $77(89.5)$ \\
\hline & $(+)$ & & & $9(10.5)$ \\
\hline
\end{tabular}

$C T$ computed tomography, $q R T-P C R$ real-time reverse transcription polymerase chain reaction disease, and hyperthyroidism. Most of the participants had the blood type of $0(+)$ and A (+) (Table 1). Mean antibody levels before and after vaccination were $4.1 \pm 4.0$ and $863.1 \pm 1381.5 \mathrm{AU} / \mathrm{mL}$, respectively (Table 1 ). Most of the participants were qRT-, qRT-PCR-, and CT-negative (qRT$\operatorname{PCR}(-) / C T(-)$; Table 1). Most of the participants did not require hospitalization.

There were no significant differences between the age groups and genders with respect to serum antibody levels ( $p=0.984$ and $p=0.357$, respectively; Table 2). Moreover, no significant differences were observed in serum antibody levels between the participants according to the presence of the comorbid diseases ( $p=0.226$ and Table 2$)$. The antibody levels in the qRT-PCR $(+)$ group were significantly higher than the qRT-PCR $(-)$ group $(p<0.05$; Table 2$)$. Also, in the $\mathrm{CT}(+)$ group, antibody levels were significantly higher than in the CT( $(-)$ group $(p<0.05$; Table 2$)$. In the $\mathrm{CT}(+) / \mathrm{qRT}$ $\mathrm{PCR}(+)$ group, the antibody level was significantly higher than the CT( $(-) / \mathrm{qRT}-\mathrm{PCR}(-)$ and $\mathrm{CT}(-) / \mathrm{qRT}-\mathrm{PCR}(+)$ or $\mathrm{CT}(+) / \mathrm{qRT}-\mathrm{PCR}(-)$ group $(p<0.05)$. On the other hand, $\mathrm{CT}(-) / \mathrm{qRT}-\mathrm{PCR}(+)$ or $\mathrm{CT}(+) / \mathrm{qRT}-\mathrm{PCR}(-)$ group exhibited significantly higher levels of antibody than the CT( - )/ qRT-PCR $(-)$ group $(p<0.05$; Table 2$)$. Moreover, antibody levels in the hospitalized group were significantly higher than in the non-hospitalized group ( $p<0.05$; Table 2$)$.
Post-vaccination antibody levels increased significantly compared to pre-vaccination levels $(p<0.05$; Table 3$)$. Moreover, a significant positive correlation was observed between the time elapsed after vaccination and the antibody levels of the participants $(r=0.343 ; p=0.000)$.

\section{Discussion}

In this study, we found that COVID-19 infection and two doses of vaccination with CoronaVac significantly increases antibody levels compared to only vaccination. Moreover, participants showing both CT and qRT-PCR positivity had significantly higher amount of antibody levels compared to participants with positivity of either CT, qRT-PCR, or none of them. Moreover, vaccination robustly increases the antibody levels against SARS-CoV-2, and this increase positively correlates with the time elapsed after vaccination.

The data of preclinical studies conducted on rodents, rabbits, and nonhuman primates regarding the efficacy and safety of the inactivated vaccines showed promising results [17-20]. Moreover, efficacy and safety of CoronaVac were investigated in phase 1 and 2 trials, and these trials showed similar efficacy at both $3 \mu \mathrm{g}$ and $6 \mu \mathrm{g}$ doses [21, 22]. Various interim results, on the other hand, showed varying efficacies 
Table 2 Antibody levels of the participants. (Note: Data are expressed as minimummaximum (min-max), median and mean \pm standard deviation (SD))

\begin{tabular}{|c|c|c|c|c|c|}
\hline & & \multicolumn{3}{|c|}{ Antibody levels (AU/mL) } & \multirow[t]{2}{*}{$p$} \\
\hline & & Min-Max & Median & Mean \pm SD & \\
\hline \multirow[t]{3}{*}{ Age } & $20-29$ & $62.6-1947.7$ & 552.9 & $618.2 \pm 423.3$ & \multirow[t]{3}{*}{$0.984^{\mathrm{K}}$} \\
\hline & $30-39$ & $0.9-1994.6$ & 453.7 & $662.8 \pm 545.0$ & \\
\hline & $\geq 40$ & $52.6-9481.0$ & 464.4 & $1535.1 \pm 2540.1$ & \\
\hline \multirow[t]{2}{*}{ Gender } & Male & $0.9-7978.8$ & 549.4 & $970.8 \pm 1376.8$ & \multirow[t]{2}{*}{$0.357^{\mathrm{K}}$} \\
\hline & Female & $52.6-9481.0$ & 488.6 & $765.0 \pm 1393.9$ & \\
\hline \multirow[t]{2}{*}{ Comorbid disease } & $(-)$ & $0.9-9481.0$ & 470.7 & $745.9 \pm 1167.0$ & \multirow[t]{2}{*}{$0.226^{\mathrm{m}}$} \\
\hline & $(+)$ & $52.6-7978.8$ & 632.3 & $1521.6 \pm 2189.4$ & \\
\hline \multicolumn{2}{|l|}{$\mathrm{CT}(-) / \mathrm{qRT}-\mathrm{PCR}(-)$} & $0.9-1732.8$ & 403.9 & $464.4 \pm 358.1$ & \multirow[t]{3}{*}{$0.000^{K}$} \\
\hline $\mathrm{CT}(+) / \mathrm{qRT}-\mathrm{PCR}(+)$ & & $62.6-9481.0$ & 1682.0 & $2212.6 \pm 2675.4$ & \\
\hline $\begin{array}{c}\mathrm{CT}(-) / \mathrm{qRT}-\mathrm{PCR}(+) \text { or } \\
\mathrm{CT}(+) / \mathrm{qRT}-\mathrm{PCR}(-)\end{array}$ & & $83.0-1554.4$ & 735.4 & $672.3 \pm 349.4$ & \\
\hline \multirow[t]{2}{*}{ qRT-PCR result } & $(-)$ & $0.9-1732.8$ & 440.2 & $501.5 \pm 387.1$ & \multirow[t]{2}{*}{$0.002^{\mathrm{m}}$} \\
\hline & $(+)$ & $62.6-9481.0$ & 770.4 & $1365.4 \pm 1994.7$ & \\
\hline \multirow[t]{2}{*}{ CT result } & $(-)$ & $0.9-1732.8$ & 448.7 & $505.5 \pm 346.2$ & \multirow[t]{2}{*}{$0.000^{\mathrm{m}}$} \\
\hline & $(+)$ & $62.6-9481.0$ & 1262.9 & $2043.1 \pm 2493.6$ & \\
\hline \multirow[t]{2}{*}{ Hospitalization } & $(-)$ & $0.9-9481.0$ & 458.0 & $671.8 \pm 1117.7$ & \multirow[t]{2}{*}{$0.000^{\mathrm{m}}$} \\
\hline & $(+)$ & $488.6-7978.8$ & 1947.7 & $2500.3 \pm 2245.2$ & \\
\hline
\end{tabular}

$C T$ computed tomography, $q R T-P C R$ real-time reverse transcription polymerase chain reaction, $K$ KruskalWallis test, $m$ Mann-Whitney $U$ test of various vaccines between 62.1 and $95 \%$ [10, 23-28]. This difference is probably due to the different effectiveness of different vaccines produced on different platforms, and higher efficacies were detected after vaccination with the mRNA vaccines [24, 25]. In addition, it has been shown that BNT162b2 vaccination resulted in higher levels of neutralizing antibodies compared to CoronaVac after the second dose [29]. Also, an interim study investigated the immunogenicity and safety of third dose of CoronaVac showed that a third dose six or more months later significantly increased the antibody levels and suggested that optimization of timing of the third dose should be carefully planned [30].

The neutralizing antibody levels against COVID-19 were suggested to correlate the protection against the disease [31-33]. In our study, higher antibody levels were observed in the groups that were infected with COVID-19 confirmed with CT and qRT-PCR compared to the diagnosis with single method and undiagnosed volunteers. This result suggests that immune system of the COVID-19-infected participants

Table 3 Pre-vaccination and post-vaccination antibody levels of the participants. (Note: Data are expressed as minimum-maximum (minmax), median and mean \pm standard deviation (SD))

\begin{tabular}{llrcc}
\hline & Min-Max & Median & Mean \pm SD & $p$ \\
\hline Pre-vaccination & $0.1-10.0$ & 3.1 & $4.1 \pm 4.0$ & $\mathbf{0 . 0 0 0}^{\mathbf{W}}$ \\
Post-vaccination & $0.9-3004.7$ & 448.0 & $649.7 \pm 652.8$ & \\
\hline
\end{tabular}

$W$ Wilcoxon signed rank test has already been activated by SARS-CoV-2 infection, and additional two doses of CoronaVac remarkably boost the antibody levels and generate a significant immune response.

Our study had some limitations. First of all, T-cell responses were not evaluated after the two doses of CoronaVac vaccine. A previous study reported low T-cell responses in the participants who were neither infected with SARSCoV-2 nor contacted with someone with COVID-19 [21]. On the other hand, virus-specific $\mathrm{CD} 8^{+}$and $\mathrm{CD} 4^{+} \mathrm{T}$ cells were detected in the patients recovered from COVID-19 [34, 35]. Therefore, it might be important to observe the T-cell responses after two doses of CoronaVac vaccination in the patients who recovered from COVID-19. Second, we did not check the individuals regarding the variant of the virus that COVID-19-infected participants had and how their immune response and antibody levels were upon CoronaVac vaccination.

\section{Conclusion}

In conclusion, two doses of CoronaVac significantly induced the antibody levels that were more prominent in the recovered COVID-19 patients. Moreover, antibody responses were significantly higher in the participants who had been diagnosed with COVID-19 by both CT and qRT-PCR. In order to provide sustainable immunity, the antibody levels should be followed throughout the pandemic. More studies are needed to observe the protection of two doses of 
vaccination against different virus variants should be investigated, and either additional doses or mixing up with other vaccines produced by using different platforms should be considered carefully.

Author contribution Conceptualization, D.O and E.A. Methodology, E.A. and N.G. Software, E.A. Validation, C.A.T., D.O., and N.G. Formal analysis, E.A. Investigation, E.A. Resources, C.A.T and N.G. Data curation, D.O. and E.A. Writing - original draft preparation, D.O. and E.A. Writing - review and editing, E.A., D.O. and N.G. Visualization, D.O. Supervision, D.O. and E.A. All authors have read and agreed to the published version of the manuscript.

\section{Declarations}

Ethical statements The study was approved by the clinical research ethics committee of our hospital (Date: 02/03/2021, Number: 1811).

Conflict of interest The authors declare no competing interests.

\section{References}

1. Tatar M, Shoorekchali JM, Faraji MR, Wilson FA (2021) International COVID-19 vaccine inequality amid the pandemic: perpetuating a global crisis? J Glob Health 11:03086. https://doi.org/10. 7189/jogh.11.03086

2. Black M, Ford J, Lee A (2021) Vaccination against COVID-19 and inequalities - avoiding making a bad situation worse. Public Health Pract (Oxf) 2:100101. https://doi.org/10.1016/j.puhip. 2021.100101

3. Alobo M (2021) Strengthened health systems are needed to tackle COVID-19 in Africa. Nat Med 27(7):1126-1127. https://doi.org/ 10.1038/s41591-021-01395-6

4. Kirkcaldy RD, King BA, Brooks JT (2020) COVID-19 and postinfection immunity: limited evidence, many remaining questions. JAMA 323(22):2245-2246. https://doi.org/10.1001/jama.2020. 7869

5. Sewell HF, Agius RM, Kendrick D, Stewart M (2020) Covid19 vaccines: delivering protective immunity. BMJ 371:m4838. https://doi.org/10.1136/bmj.m4838

6. Suthar MS, Zimmerman MG, Kauffman RC et al (2020) Rapid generation of neutralizing antibody responses in COVID-19 patients. Cell Rep Med 1(3)

7. Yan ZP, Yang M, Lai CL (2021) COVID-19 Vaccines: a review of the safety and efficacy of current clinical trials. Pharmaceuticals (Basel) 14(5). https://doi.org/10.3390/ph14050406

8. Organization WH (2021) Draft landscape and tracker of COVID19 candidate vaccines. World Health Organization, Genova, Switzerland

9. Kyriakidis NC, López-Cortés A, González EV et al (2021) SARSCoV-2 vaccines strategies: a comprehensive review of phase 3 candidates. NPJ Vaccines 6(1):28. https://doi.org/10.1038/ s41541-021-00292-w

10. Tanriover MD, Doğanay HL, Akova M et al (2021) Efficacy and safety of an inactivated whole-virion SARS-CoV-2 vaccine (CoronaVac): interim results of a double-blind, randomised, placebocontrolled, phase 3 trial in Turkey. Lancet 398(10296):213-222. https://doi.org/10.1016/s0140-6736(21)01429-x

11. Yu ED, Grifoni A, Sutherland A et al (2021) Balanced cellular and humoral immune responses targeting multiple antigens in adults receiving a quadrivalent inactivated influenza vaccine. Vaccines (Basel) 9(5). https://doi.org/10.3390/vaccines9050426

12. Al Kaabi N, Zhang Y, Xia S et al (2021) Effect of 2 inactivated SARSCoV-2 vaccines on symptomatic COVID-19 infection in adults: a randomized clinical trial. JAMA 326(1):35-45. https://doi.org/10.1001/ jama.2021.8565

13. Awadasseid A, Wu Y, Tanaka Y, Zhang W (2021) Current advances in the development of SARS-CoV-2 vaccines. Int J Biol Sci 17(1):8-19. https://doi.org/10.7150/ijbs.52569

14. Iversen PL, Bavari S (2021) Inactivated COVID-19 vaccines to make a global impact. Lancet Infect Dis 21(6):746-748. https:// doi.org/10.1016/s1473-3099(21)00020-7

15. Seow J, Graham C, Merrick B et al (2020) Longitudinal observation and decline of neutralizing antibody responses in the three months following SARS-CoV-2 infection in humans. Nat Microbiol 5(12):1598-1607. https://doi.org/10.1038/ s41564-020-00813-8

16. Holshue ML, DeBolt C, Lindquist S et al (2020) First case of 2019 novel coronavirus in the United States. N Engl J Med 382(10):929-936. https://doi.org/10.1056/NEJMoa2001191

17. Gao Q, Bao L, Mao H et al (2020) Development of an inactivated vaccine candidate for SARS-CoV-2. Science 369(6499):77-81. https://doi.org/10.1126/science.abc1932

18. Wang H, Zhang Y, Huang B et al (2020) Development of an inactivated vaccine candidate, BBIBP-CorV, with potent protection against SARS-CoV-2. Cell 182(3):713-21.e9. https://doi.org/10. 1016/j.cell.2020.06.008

19. Mohandas S, Yadav PD, Shete-Aich A et al (2021) Immunogenicity and protective efficacy of BBV152, whole virion inactivated SARS- CoV-2 vaccine candidates in the Syrian hamster model. iScience 24(2):102054. https://doi.org/10.1016/j.isci.2021.102054

20. Ganneru B, Jogdand H, Daram VK et al (2021) Th1 skewed immune response of whole virion inactivated SARS CoV 2 vaccine and its safety evaluation. iScience 24(4):102298. https://doi. org/10.1016/j.isci.2021.102298

21. Zhang Y, Zeng G, Pan H et al (2021) Safety, tolerability, and immunogenicity of an inactivated SARS-CoV-2 vaccine in healthy adults aged 18-59 years: a randomised, double-blind, placebocontrolled, phase 1/2 clinical trial. Lancet Infect Dis 21(2):181192. https://doi.org/10.1016/s1473-3099(20)30843-4

22. Wu Z, Hu Y, Xu M et al (2021) Safety, tolerability, and immunogenicity of an inactivated SARS-CoV-2 vaccine (CoronaVac) in healthy adults aged 60 years and older: a randomised, doubleblind, placebo-controlled, phase 1/2 clinical trial. Lancet Infect Dis 21(6):803-812. https://doi.org/10.1016/s1473-3099(20) 30987-7

23. Logunov DY, Dolzhikova IV, Shcheblyakov DV et al (2021) Safety and efficacy of an rAd26 and rAd5 vector-based heterologous prime-boost COVID-19 vaccine: an interim analysis of a randomised controlled phase 3 trial in Russia. Lancet 397(10275):671-681. https://doi.org/10.1016/s0140-6736(21) 00234-8

24. Baden LR, El Sahly HM, Essink B et al (2021) Efficacy and Safety of the mRNA-1273 SARS-CoV-2 Vaccine. N Engl J Med 384(5):403-416. https://doi.org/10.1056/NEJMoa2035389

25. Polack FP, Thomas SJ, Kitchin N et al (2020) Safety and Efficacy of the BNT162b2 mRNA Covid-19 Vaccine. N Engl J Med 383(27):2603-2615. https://doi.org/10.1056/NEJMoa2034577

26. Voysey M, Clemens SAC, Madhi SA et al (2021) Safety and efficacy of the ChAdOx1 nCoV-19 vaccine (AZD1222) against SARS-CoV-2: an interim analysis of four randomised controlled trials in Brazil, South Africa, and the UK. Lancet 397(10269):99111. https://doi.org/10.1016/s0140-6736(20)32661-1

27. Sadoff J, Gray G, Vandebosch A et al (2021) Safety and efficacy of single-dose Ad26.COV2.S vaccine against Covid-19. N Engl J Med 384(23):2187-201. https://doi.org/10.1056/NEJMoa2101544 
28. Jara A, Undurraga EA, González C et al (2021) Effectiveness of an inactivated SARS-CoV-2 vaccine in Chile. N Engl J Med 385(10):875-884. https://doi.org/10.1056/NEJMoa2107715

29. Lim WW, Mak L, Leung GM et al (2021) Comparative immunogenicity of mRNA and inactivated vaccines against COVID-19. Lancet Microbe 2(9)

30. Pan $\mathrm{H}, \mathrm{Wu} \mathrm{Q}$, Zeng $\mathrm{G}$ et al (2021) Immunogenicity and safety of a third dose, and immune persistence of CoronaVac vaccine in healthy adults aged 18-59 years: interim results from a double-blind, randomized, placebo-controlled phase 2 clinical trial. medRxiv. 2021:2021.07.23.21261026. https://doi.org/10.1101/ 2021.07.23.21261026

31. Khoury DS, Cromer D, Reynaldi A et al (2021) Neutralizing antibody levels are highly predictive of immune protection from symptomatic SARS-CoV-2 infection. Nat Med 27(7):1205-1211. https://doi.org/10.1038/s41591-021-01377-8
32. Koch T, Mellinghoff SC, Shamsrizi P (2021) Correlates of vaccine-induced protection against SARS-CoV-2. Vaccines (Basel) 9(3). https://doi.org/10.3390/vaccines9030238

33. Earle KA, Ambrosino DM, Fiore-Gartland A et al (2021) Evidence for antibody as a protective correlate for COVID-19 vaccines. Vaccine 39(32):4423-4428. https://doi.org/10.1016/j. vaccine.2021.05.063

34. Grifoni A, Weiskopf D, Ramirez SI et al (2020) Targets of T cell responses to SARS-CoV-2 coronavirus in humans with COVID19 disease and unexposed individuals. Cell 181(7):1489-501.e15. https://doi.org/10.1016/j.cell.2020.05.015

35. Sekine T, Perez-Potti A, Rivera-Ballesteros O et al (2020) Robust $\mathrm{T}$ cell immunity in convalescent individuals with asymptomatic or mild COVID-19. Cell 183(1):158-68.e14. https://doi.org/10. 1016/j.cell.2020.08.017 